\title{
Separação: o doloroso processo de dissolução da conjugalidade
}

\author{
Terezinha Féres-Carneiro \\ Pontifícia Universidade Católica do Rio de Janeiro
}

\begin{abstract}
Resumo
Este estudo teve como objetivo investigar como homens e mulheres das camadas médias da população vivenciam o processo de dissolução do casamento e buscam reconstruir suas identidades individuais, após a separação conjugal. Foi realizada uma pesquisa de campo com 16 mulheres e 16 homens das camadas médias da população carioca, com idades variando de 25 a 35 anos ( $1^{\underline{a}}$ faixa etária) e de 45 a 55 anos (2ª faixa etária), separados legalmente ou não do primeiro casamento e que ainda não estavam recasados. Os dados foram levantados através de entrevistas semi-estruturadas. Não foram encontradas diferenças relevantes entre os dois grupos etários, entretanto foram constatadas diferenças entre as vivências masculinas e femininas em relação às seguintes categorias de análise: desejo de separação, decisão de separação, processo de separação e reconstrução da identidade individual.
\end{abstract}

Palavras-chave: separação conjugal; desejo de separação; decisão de separação; conjugalidade; identidade individual

\begin{abstract}
Marital separation: the painful process of the dissolution of conjugality. The purpose of this study was to investigate how middle class men and women experience the process of marriage dissolution and seek to reconstruct their individual identity after marital separation. A field study was conducted with 16 middle class women and 16 middle class men, living in Rio de Janeiro. Their age range varied from 25 to 35 years $\left(1^{\text {st }}\right.$ age group) and from 45 to 55 years ( $2^{\text {nd }}$ age group). All subjects had been married once, were separated and had not remarried again. The data were obtained through semi-structured interviews. Relevant differences were not observed between the two age groups, although differences between male and female experiences were examined according to the following evaluation categories: willingness to separate, decision to separate, separation process and reconstruction of individual identity.
\end{abstract}

Key-words: marital separation; willingness to separate; decision to separate; conjugality; individual identity

$\mathrm{N}$ a nossa clínica como terapeuta de casal, temos constatado que é cada vez maior o número de casais que procuram atendimento psicológico trazendo como questão principal o tema da separação. Temos observado também que, nestes casais, são quase sempre as mulheres que manifestam o desejo de se separarem enquanto os maridos, na maior parte das vezes, desejam manter o casamento. Em Féres-Carneiro (1995), constatamos uma maior possibilidade das mulheres realizarem mudanças, assim como de romperem o casamento.

O casamento implica a construção de uma nova identidade para os cônjuges, de um "eu-conjugal” na definição de Singly (1988), que vai se construindo através das interações estabelecidas entre eles. Willi (1995), ao definir o casamento como uma relação diferente de todas as outras, argumenta que quando duas pessoas decidem que viverão juntas, cada uma terá de se modificar internamente e se reorganizar.

No processo de separação, a identidade conjugal, construída no casamento, vai aos poucos se desfazendo, levando os cônjuges a uma redefinição de suas identidades individuais. A separação, descrita por Caruso (1968/1989) como uma das mais dolorosas experiências pelas quais pode passar o ser humano, é um processo complexo, vivido em diferentes etapas e em diferentes níveis, ou seja, nos pensamentos secretos de cada membro do casal, no diálogo entre eles e na explicitação para o contexto social que os circunda. Para o autor, estudar a separação amorosa significa estudar a presença da morte na vida, ou seja, na separação há uma sentença de morte recíproca: “o outro morre em vida mas morre dentro de mim... e eu também morro na consciência do outro" (p. 20).

Muitos casais procuram terapia com a demanda explícita de "se separarem bem" e ao longo do processo terapêutico entram em contato com o desejo, muitas vezes inconsciente, de não romperem a relação, e mantêm-se casados. Por outro lado, há casais que buscam atendimento psicológico com a demanda manifesta de "manterem o casamento" e no processo de terapia de casal se separam. Como enfatizamos em Féres- 
Carneiro (1995), o compromisso da terapia é com a promoção da saúde emocional dos membros do casal e não com a ruptura ou a manutenção do casamento.

Com o objetivo de investigar como homens e mulheres das camadas médias da população carioca vivenciam a construção e a dissolução do casamento, desenvolvemos um projeto integrado de pesquisa intitulado "Casamento e separação: um estudo sobre a construção e a dissolução do laço conjugal na contemporaneidade”. Para estudarmos tais processos, desdobramos o referido projeto em três subprojetos: (1) casamento contemporâneo: construção da identidade conjugal; (2) separação conjugal: dissolução da conjugalidade e reconstrução da identidade; e (3) construção e dissolução do laço conjugal na terapia de casal.

Os resultados do subprojeto 1 estão publicados em Féres-Carneiro (2001) e o subprojeto 3 encontra-se ainda em desenvolvimento. Neste artigo, apresentaremos os resultados do subprojeto 2, que teve como objetivo investigar o processo de dissolução da conjugalidade e a conseqüente reconstrução das identidades individuais, comparando também as vivências masculinas e femininas em relação à manifestação de atitudes e sentimentos frente à separação conjugal.

\section{Separação conjugal: valorização ou desqualificação do casamento?}

Será que a tese defendida por Berger e Kellner (1970), de que o casamento é para os cônjuges a principal área de autorealização social e a base dos relacionamentos na esfera privada, poderia ser questionada face ao crescente número de separações conjugais na sociedade contemporânea? O que constatamos, na nossa prática clínica e nas investigações que vimos realizando, é que os cônjuges se divorciam não porque desqualificam o casamento, mas porque o valorizam tanto que não aceitam que a relação conjugal não corresponda às suas expectativas. Portanto, longe de significar uma desvalorização do casamento, o divórcio reflete uma exacerbada exigência dos cônjuges. Assim, na maior parte dos casos, os divorciados acabam caminhando para o recasamento.

A estimativa de ocorrência de divórcio nos Estados Unidos é de $50 \%$ para os que se casam pela primeira vez, e de $60 \%$ para os que se casam pela segunda vez (Gottman, 1994; Rasmussen \& Ferraro, 1991). No Brasil, os últimos números divulgados pelo Anuário Estatístico Brasileiro (IBGE, 1996) indicam aproximadamente um divórcio para cada quatro casamentos, e mostram que $71 \%$ dos casos de separações judiciais não consensuais, encerradas em primeira instância, foram requeridas pelas mulheres.

Muito tem sido publicado sobre o divórcio na literatura internacional, mas grande parte dessa literatura aborda sobretudo a questão das causas (e.g., Cleek \& Pearson, 1985; Gottman, 1994; White, 1990) e das conseqüências (e.g., Demo \& Acock, 1988; Kitson \& Morgan, 1990) das separações.

Em nosso país, os estudos também investigam, sobretudo, as causas e as conseqüências do divórcio (e.g., Cavalcante, 1993; Jablonski, 1998; Maldonado, 1986). São escassas as pesquisas, como as que desenvolveu Veiga-da-Silva (1997, 2001), sob nossa orientação, enfatizando, além das condições sociais, os fatores psicológicos implicados no processo de separação.

\section{Método}

\section{Participantes}

A pesquisa de campo foi realizada com 32 sujeitos (16 mulheres e 16 homens), com idades variando de 25 a 35 ( $1^{\underline{a}}$ faixa etária) e de 45 a 55 anos ( $2^{\underline{a}}$ faixa etária), pertencentes às camadas médias da população carioca, separados legalmente ou não, do primeiro casamento com duração mínima de três anos, com filho(s) deste casamento, e que ainda não estavam recasados.

\section{Procedimentos}

Os dados foram levantados através de entrevistas semiestruturadas cuja estruturação invisível contemplou os seguintes temas: desejo de separação, decisão de separação, processo de separação e reconstrução da identidade individual.

As entrevistas gravadas e transcritas foram analisadas através da metodologia de análise de discurso, tal como proposto por Bardin (1979), tendo sido privilegiados os aspectos qualitativos.

\section{Resultados e Discussão ${ }^{1}$}

Foram estabelecidas as seguintes categorias de análise: desejo de separação, decisão de separação, processo de separação e reconstrução da identidade individual.

\section{Desejo de separação}

O desejo de separação aparece tanto na fala das mulheres como na fala dos homens, de ambas as faixas etárias, como um desejo predominantemente feminino.

...eu, com 26 anos quis me separar: quer saber de uma coisa? Posso até ter me precipitado, mas eu não estava a fim disso para mim. Então eu fiz uma opção, não queria e acabou. Meio que na cara e na coragem eu me separei com um filho de um ano e uma filha de três e fui à luta... (M.1.4)

O desejo de separar surgiu por parte da minha ex-mulher, ela já vinha com essa idéia há algum tempo mas eu fui tentando acalmá-la, falando que ela estava tomando uma atitude precipitada. Chegou um dia que ela não quis mais esperar, disse que queria o divórcio. (H.2.4)

....as atitudes que ele estava tomando eram de quem queria se separar, mas aí como ele tinha saído de casa para dar um tempo, eu deixei passar as festas de fim-de-ano, e dia dois de janeiro eu virei para ele e disse: Agora que já passou Natal e Reveillon você já decidiu o que quer? Ele falou “ainda não”, aí eu disse, na dúvida, você sai de casa de vez. (M.1.8)

Estes resultados confirmam os dados brasileiros, tanto de âmbito judiciário (IBGE, 1996) como da clínica (Féres- 
Carneiro, 1995), assim como dados internacionais que indicam que a grande maioria das demandas de separação é feminina (Gottman, 1994; Rasmussen \& Ferraro, 1991). Magalhães (1993) e Féres-Carneiro (1995, 1997), investigando concepções de casamento, verificaram que enquanto as mulheres concebem casamento como "relação amorosa", para os homens, casamento é sobretudo “constituição de família”. A demanda predominantemente feminina de separação pode ser compreendida como uma das conseqüências desta diferença na concepção de conjugalidade para homens e mulheres. Tendo em vista o modo como definem casamento, para as mulheres, quando a relação conjugal não vai bem, sobretudo na sua vertente amorosa, a separação parece inevitável.

No discurso sobre o desejo de separação, grande parte das mulheres, de ambos os grupos etários, relacionou a dificuldade de manterem a relação conjugal ao fato de ambos os cônjuges terem "se casado muito cedo" (com menos de 23 anos).

Eu me casei muito nova, com 18 anos... na casa dos meus pais eu estava acostumada a ter as coisas da minha maneira, um pouco mimadinha... (M.1.5)

...mas acho que ouve um erro sim, um dos erros eu acho que foi a influência da minha família, porque eu nunca consegui me separar da minha família, da minha mãe. Eu casei nova, com 22 anos... (M.2.4)

Como eu casei muito nova, com 22 anos e ele também com a mesma idade, eu acho que a gente atravessa um processo assim de descobrimento do mundo e da vida que na verdade isso vai mudando. Então, era como se fôssemos dois adolescentes vivendo um casamento adolescente, aí eu acho que o próprio fato de ir se tornando mais homem, mais mulher, a gente vai querendo outras coisas. (M.2.3)

Estudos como o de Faria-Leitão (1996) e de Zagury (2000) mostram como, nas camadas médias da população brasileira, a adolescência tem sido prolongada. Na nossa experiência clínica, também temos cuidado de famílias destes segmentos sociais cujos filhos, às vezes já com 30 anos, ainda dependem financeiramente dos pais e nem consideram a possibilidade de saírem da casa dos pais. Este prolongamento da vivência da adolescência pode explicar em parte, como aparece na fala dos entrevistados, a dificuldade que tiveram de se manterem no casamento. Na medida em que as dificuldades e os conflitos da adolescência permanecem na vivência dos jovens cônjuges, falta a eles a maturidade requerida pela vida compartilhada, para a manutenção da conjugalidade.

A traição por parte dos homens foi também um fator muito enfatizado pelas mulheres de todas as idades em suas falas sobre o desejo de separação.

Me doei completamente a uma pessoa que me traiu, minha vida desmoronou, então tive que reconstruir tudo sozinha. Muita coisa mudou, deixei de pensar nele, para começar a pensar em mim. Pensar no que eu quero construir para mim,...independente de ter ou não uma pessoa ao meu lado. (M.1.2)
Quando ele voltou de uma viagem, eu disse que queria realmente me separar, não ia voltar atrás e não queria mais transar com ele. Ele já tinha outra mulher, então para ele foi mais fácil aceitar. (M.2.2)

Eu descobri que ele estava com outra pessoa. Foi muito difícil para mim. A traição é uma coisa horrorosa. Tem a coisa da lealdade, a pessoa que a gente acreditava, de repente a gente descobre que não é aquela pessoa, ... o fato é que eu descobri a relação dele com outra mulher... Foi eticamente feio. (M.2.8)

Os homens, ao ressaltarem o desejo predominantemente feminino de separação também o relacionaram à sua própria traição.

Quando ela viajou eu tive um caso. Foi uma paixão meio fulminante, só que eu segurei a onda porque achava que aquilo ia passar, enquanto que, com ela, eu achava que ia durar. Mas ela quis se separar.(H.1.2)

... na verdade, aconteceu outra pessoa. A minha mulher encontrou uma carta dessa outra menina e, a partir daí, ela não quis mais nenhuma espécie de acordo. O desejo de separação foi instantâneo. Na verdade, esse casamento não teve início, meio e fim. Ele foi cortado no meio, em função dessa história paralela. (H.2.7)

A traição masculina apareceu tanto no discurso das mulheres como no dos homens, de ambas as faixas etárias, associada ao desejo feminino de separação. Diferentes estudos realizados em culturas diversas ressaltam o fato de os homens traírem mais que as mulheres (Buss \& Barnes, 1988; Goldenberg, 2000; Jablonski, 1998; Nolasco, 1998; Trevisan, 1998). Nolasco (1998) discute como o sentimento de identidade masculina está relacionado ao de identidade sexual. Assim, relacionamentos sexuais freqüentes e numerosos com diferentes mulheres é, muitas vezes, um modo que os homens encontram de afirmação da sua masculinidade.

Goldenberg (2000) assinala a diferença de sentimentos associados à infidelidade masculina e à feminina ressaltando que, em investigação por ela realizada, apenas as mulheres relataram sentimento de culpa pela traição. Na medida em que a traição masculina é muito mais aceita culturalmente que a feminina, os homens conseguem lidar com a infidelidade de modo muito mais tranqüilo que as mulheres.

\section{Decisão de separação}

Em relação à decisão de separação, a maioria das mulheres de ambos os grupos descreve como sendo delas a tomada de decisão.

Olha, acho que ambos já tinham decidido muito antes de acontecer, mas quem pronunciou as palavras e disse "vamos nos separar” fui eu. (M.1.3)

Aí falei: vamos nos separar, não tá dando, vamos mesmo. E ele disse: vamos... A iniciativa foi minha. Agora eu te digo uma coisa: depois que eu me separei eu não tive nenhum segundo de 
arrependimento, nem nas piores crises de solidão, ... eu gosto muito de ficar sozinha. Eu me dou muito bem comigo mesma. ( M.2.1)

É, na verdade eu decidi que queria me separar e ele saiu de casa. (M.2.3)

Na percepção dos homens, também sem distinção de idade, a decisão de separação é descrita predominantemente como feminina e, às vezes, como uma decisão mútua.

Quem começou a falar sobre separação foi ela. (H.1.8)

Ela disse que queria conversar comigo, eu tinha acabado de chegar de viagem, e pedi para que conversássemos outro dia. Ela disse que não dava mais para adiar, e aí começou a falar. Disse que ausente por ausente, era melhor nos separarmos, que já tinha esperado demais e que queria resolver tudo o mais rápido possível... Eu simplesmente aceitei. ( H.2.4)

...ambos chegamos à conclusão de que não dava mais. A gente estava começando a entrar numa fase muito difícil, de um começar a agredir o outro, com palavras e tal. Então, a gente resolveu se separar e foi tudo de comum acordo... a gente sentou, conversou e viu que o melhor era mesmo a separação. (H.1.7)

Na medida em que o desejo de separação, como vimos anteriormente, tanto no discurso das mulheres como no dos homens, é um desejo predominantemente feminino, seria esperado, como conseqüência, que a decisão de separação fosse também uma atitude tomada mais pelas mulheres do que pelos homens. Além disso, o fato de os homens dissociarem, mais que as mulheres, o sexo da afetividade, como demonstram vários estudos (e.g., Buss \& Barnes, 1988; Cherman, 1993; Goldenberg, 2000; Vaitsman, 1994), permitiria a eles, com mais facilidade do que às mulheres, permanecerem no casamento sem tantos conflitos internos, mesmo quando insatisfeitos com a relação amorosa. Afinal, na concepção masculina de casamento, como vimos anteriormente, a constituição de família é um fator muito mais relevante do que a relação amorosa.

Apesar de a decisão de separação ser predominantemente feminina, são as mulheres, de ambos os grupos, que aparecem tomando a iniciativa para conversar e buscando alternativas para manter o relacionamento.

Meu filho tinha 1 ano e meio e tanto eu quanto o pai dele estávamos descontentes. A coisa foi esfriando, eu pessoalmente ainda tentei resgatar nossa relação, mas nós já estávamos muito distantes . (M.1.7)

Tentei reavaliar as coisas, o que nós podíamos fazer para mudar. Ele não quis. Eu tentei reconquistá-lo. Passei oito meses correndo atrás dele. Hoje eu me arrependo. (M.2.8)

Eu sempre lutei muito pelo nosso casamento, fiz de tudo para que isso não acontecesse, minha consciência está tranqüila.

(M.1.2.)
Para Giddens (1992), as mulheres ficaram especialistas nas técnicas de intimidade enquanto os homens se especializaram nas técnicas de sedução. Em Féres-Carneiro (1995), constatamos que, mais desinstaladas e buscando mudanças, as mulheres valorizam, muito mais que os homens, as conversas íntimas. Em vários outros estudos (e.g., Dias, 2000; Giddens,1992; Goldenberg, 1991; Singly, 1993), as mulheres aparecem querendo discutir e conversar sobre a relação. É possível também que o fato de as mulheres desejarem, mais que os homens, a separação, provoque nelas um sentimento de responsabilidade maior, que as leva a buscarem alternativas para o relacionamento, antes da tomada final de decisão pela sua ruptura.

\section{Processo de separação}

O processo de separação foi descrito por homens e mulheres, de ambas as faixas etárias, como muito difícil e sofrido. Nas falas femininas, a desilusão foi muito ressaltada.

Olha, quando você acaba um casamento... para mim foi muito difícil, tanto foi difícil que depois de 2 anos separados eu voltei a morar com ela. Mas legalmente eu estava separado. Fiquei mais um ano e meio com ela para confirmar que não dava mais certo. Foi muito sofrido. (H.1.7)

Foi realmente difícil, tanto para nós como para as crianças. Todos nós sofremos muito. Bom, o processo foi complicado, porque ela não aceitou as minhas condições... então foi aquele stress. E os filhos sempre envolvidos nisso tudo. É um processo muito complicado, muito sofrido, difícil mesmo, envolvendo família e justiça. (H.2.5)

Não foi fácil. A gente saiu brigado um com o outro. Durante o primeiro mês a gente nem se falou, eu resolvi ligar depois de um tempo para acertar todo o processo legal... Nos primeiros meses eu fiquei super deprimida, queria que meu casamento fosse um conto de fadas e não foi. (M.1.1)

Foi difícil, está sendo muito difícil para mim...tanto para mim quanto para M. Puxa! Sonhei tanto com um casamento perfeito. Acho que aquele sonho que temos quando pequeno, que o príncipe encantado virá em um cavalo branco te buscar. (M.2.2)

Toda separação implica a vivência de muito sofrimento. Caruso (1989) afirma que estudar a separação amorosa significa estudar a presença da morte na vida, ou seja, os cônjuges vivenciam uma sensação de morte recíproca: cada um tem que morrer em vida dentro do outro. Como ressaltamos em Féres-Carneiro (1998), embora a separação possa ser, às vezes, a melhor solução para um casal cujos membros não se consideram capazes de continuar tentando ultrapassar suas dificuldades, ela é sempre vivenciada como uma situação extremamente dolorosa, havendo um luto a ser elaborado.

Enquanto os homens enfatizaram mais os sentimentos de frustração e fracasso no processo de separação, as mulheres ressaltaram sobretudo a vivência da mágoa e da solidão. 
Foi horrível. Um sentimento de frustração, de você não ter conseguido fazer aquilo que tinha planejado fazer. É um sentimento de posse, porque a minha filha vai ter que conviver com outras pessoas. Também o meu orgulho de macho ficou ferido, penso que essa mulher irá se relacionar com outros homens. (H.1.3)

Eu passei por várias fases. A primeira foi um sentimento de fracasso. Eu venho de uma família que ninguém nunca tinha se separado antes de mim. (H.2.2)

Não foi fácil para mim, porque eu tinha um filho ainda novo, e eu tinha medo de ficar sozinha nessa separação, mas eu não tive grandes problemas com a justiça, ele aceitou numa boa a decisão do juiz e paga a pensão certinha. (M.1.3)

Eu fiquei com muita mágoa. Primeiro uma mágoa com ele, óbvio, do tipo assim: estou sendo chifrada, fui trocada. E depois me senti magoada comigo, de eu não ter me tocado, de não ter percebido. Também senti muita solidão com relação a criar uma criança sozinha. (M.1.6)

Esta diferença de sentimentos nas vivências masculinas e femininas do processo de separação conjugal pode estar relacionada também ao modo distinto de homens e mulheres conceberem casamento, já ressaltado anteriormente. Assim, quando o projeto de "constituir família" é interrompido com a separação, os homens se sentem sobretudo "frustrados" e "fracassados", e quando a "relação de amor" termina, as mulheres se sentem sobretudo "magoadas” e "sozinhas”.

Ao se referirem aos filhos no processo de separação dos pais, a maior parte dos homens, sem distinção de idade, descreveu, principalmente, sentimentos de preocupação e sofrimento, e ressaltou, algumas vezes, o fato de as crianças terem "ficado mal” com a separação.

Com relação ao sentimento, ficou a frustração... Eu conversei com ela, então a coisa que mais pesou foi não estar mais sempre com a C... Com relação à C., eu acho que ela sentiu um pouco, mas o clima estava ficando tão pesado que no fundo foi melhor para ela também. (H.1.2)

A minha primeira filha reagiu mal. Porque eu fiquei com ela até ela completar 3 anos e ela era muito ligada a mim. Eu que levava para passear, dava banho, botava para dormir, contava historinha. Não que a mãe não fizesse, mas eu fazia um pouquinho mais. (H.1.8)

Com relação aos filhos, a coisa foi meio complicada. Acho que o mais velho não sentiu tanto, mas o mais novo ficou muito mal. Acho que nós não tivemos a competência necessária para tentar passar uma coisa boa para eles. Essa coisa sempre repercutiu com relação as crianças. O filho menor teve problemas nos estudos, que ele carrega até hoje. (H.2.2)

Por outro lado, a maioria das mulheres dos dois grupos etários, ao se referirem aos filhos no processo de separação, enfatizou que os mesmos não "ficaram mal” com a separação dos pais.
Ela conviveu muito pouco com ele, afinal quando nos separamos ela tinha só quatro anos... Hoje em dia ela lida com isso naturalmente, não é um horror para a criança ser filha de pais separados. (M.1.1)

Acho que as crianças não sofrem quando vêem que o pai e a mãe se separaram mas que a família não se separou. Os meus filhos hoje em dia vivenciam isso bem, acham que têm duas casas, duas famílias, vivem felizes com essa situação. Na hora que eles querem eles têm o pai. (M.2.6)

Para mim, acho que eles estão bem. É lógico que devem ter sentido alguma coisa, a ausência, bem ou mal, ele estava sempre dentro de casa. Mas nada que traga grandes problemas. (M.2.7)

A percepção distinta de homens e mulheres em relação aos filhos, no processo de separação dos pais, parece marcada pelo fato de, em todos os casos, os filhos terem permanecido com a mãe (o que quase sempre ocorre). Afastados do cotidiano dos filhos, os homens sofrem mais com a ausência destes e tendem a projetar seu sofrimento neles que, certamente, também sentem a ausência dos pais, mas não necessariamente "ficam mal” por causa disto. As mulheres, na medida em que acompanham de perto o cotidiano dos filhos, têm mais controle sobre o que vai ocorrendo com eles, o que as tranqüiliza mais e as faz percebê-los "sem tantos problemas".

\section{Reconstrução da identidade individual}

Em relação ao processo de reconstrução da identidade individual não houve também diferença entre as faixas etárias. A maior parte dos homens relatou como difíceis os primeiros tempos após a separação.

No início eu parecia um peixe fora d’água. Meus amigos me chamavam para sair e era engraçado. A coisa boa disso é pensar que o novo pode rolar. A parte ruim foi deixar de ter a minha família. (H.1.3)

Difícil, eu acho que tomei um susto grande, achei que seria muito mais complicado do que foi. Mas não vou te dizer que superei com facilidade. Como te falei, fui vivendo minha vida. Continuo sendo o mesmo J. de antes, não fiquei mais amargurado ou desiludido. (H.2.4)

Tanto os homens como as mulheres ressaltaram a vivência da liberdade como um aspecto positivo decorrente da separação conjugal.

Hoje em dia eu tenho uma liberdade que eu não tinha antes, isso é óbvio! No entanto, eu nem saio muito, mas eu sei que se eu quiser eu posso sair com os meus amigos que não vai ter ninguém me controlando em casa. (H.1.7)

Você fica na sua vida, você é dono de você, não tem ninguém mandando em você, ninguém te obrigando a fazer nada, isso de repente você até começa a achar que é bom. É bom se sentir livre e independente. Eu já estou começando a me sentir assim. (M.2.7) 
A solidão foi descrita por homens e mulheres como uma dificuldade a ser enfrentada após a separação.

Passei por momentos extremamente complicados de solidão... Sabe, para mim, ficar sozinho é muito difícil, não me lembro de ter ficado sozinho por muito tempo, não consigo. É claro que tive alguns momentos de solidão, passei momentos só mas aproveitei para fazer uma reavaliação da minha vida e cuidar um pouco de mim. (H.2.5)

Então a solidão é um problema sério. Eu me sinto sozinha como mulher. Gostaria de me sentir protegida, de poder compartilhar com alguém as coisas... (M.1.4)

As mulheres descreveram uma sensação de alívio e um sentimento de maior responsabilidade e de auto-valorização decorrentes da separação.

Olha, logo que eu me separei me senti extremamente aliviada. Depois veio uma sensação de desamparo, de medo, de solidão, de dúvida. E por último veio o melhor de tudo, que foi a possibilidade de resgatar uma série de coisas individuais. (M.1.5)

Eu amadureci muito. Por um lado, eu tive muita coragem de tomar a decisão e me separar, dar uma basta no meu sofrimento. Eu me valorizei naquele momento, e com isso eu acho que ganhei respeito dele, da minha família, dos meus amigos. Sou mais independente, acho que minha auto-estima está boa, tenho mais segurança em mim. (M.1.1)

Foram as mulheres também que enfatizaram com mais clareza os movimentos do lento processo de reconstrução da identidade individual.

É uma reconstrução, é realmente um processo muito longo e complicado porque você se modifica, deixa de ser dois, o casal, e passa a ser mais responsável pelas coisas que diz ou faz. Assim eu pude me conhecer melhor, conheci uma outra pessoa aqui dentro de mim, comecei a reconhecer as coisas boas que tenho sem precisar dos outros. (M.1.2)

A gente tem essa imagem de que o casamento é uma coisa de um só, mas na verdade não é. São duas pessoas, que têm uma ligação forte, às vezes nos confundimos e fica uma coisa tão emaranhada que a gente não sabe definir até que ponto é você ou é ele. E para mim foi no sentido de poder me olhar mais como indivíduo e buscar minha identidade... (M.2.7)

Assim, em relação à reconstrução da identidade individual, tanto os homens como as mulheres de ambas as faixas etárias ressaltaram a dificuldade deste lento processo marcado, por um lado, por muita solidão mas, por outro, por uma vivência gratificante de liberdade. A dificuldade de "ficar só” foi mais enfatizada nas falas masculinas, enquanto os sentimentos de alívio e de maior auto-valorização apareceram apenas nas falas das mulheres, que também puderam descrever melhor o processo de reconstrução da identidade individual.

Estes resultados estão em consonância com os dados de estudos anteriores. Em Féres-Carneiro (1995, 1997) e Dias
(2000), as mulheres se mostraram muito mais questionadoras, buscando mudanças e com maiores possibilidades de entrarem em contato com seus sentimentos que os homens. Giddens (1992) e Singly (1993) ressaltam a tendência, predominantemente feminina, de discutir a relação conjugal e de explicitar os sentimentos dos cônjuges na relação. Estas características femininas podem explicar, em parte, o fato de as mulheres terem relatado maiores ganhos com a separação conjugal que os homens e terem descrito com mais clareza o processo de reconstrução da identidade individual. Além disso, estudos sobre o recasamento, como os de FéresCarneiro (1987) e de Woods (1987), mostram uma maior dificuldade dos homens de ficarem sós e uma tendência destes a se recasarem muito mais rapidamente que as mulheres.

\section{Considerações finais}

Na medida em que não foram encontradas diferenças relevantes entre os dois grupos etários estudados, pode-se considerar que a idade não é um fator importante na vivência do processo de dissolução da conjugalidade. Entretanto, as atitudes e os sentimentos de homens e mulheres se contrastaram em muitas das situações avaliadas, apontando para a importância do gênero como fator diferenciador na vivência da separação conjugal. Delinearam-se com clareza um desejo e uma decisão de separação predominantemente femininos, o que não significa, sem dúvida, que a intensidade da dor vivenciada, neste processo, por homens e mulheres seja diferente. Homens sentindo-se sobretudo frustrados e fracassados, e mulheres vivenciando principalmente mágoa e solidão, todos eles experimentam um profundo sentimento de dor no processo de ruptura do relacionamento conjugal.

Embora vivenciando a mesma dor, homens e mulheres comportam-se diferentemente e manifestam de forma distinta seus sentimentos em relação à separação e àquilo que pode tê-la provocado. Tais diferenças estão muito mais relacionadas a questões culturais do que a distinções biológicas entre os sexos. Quando homens e mulheres apontam a infidelidade masculina como uma das causas da separação, ao mesmo tempo em que estão ressaltando que a traição masculina é mais tolerada culturalmente do que a feminina, estão também explicitando uma reação maior das mulheres que, traídas, desejam a separação nos relacionamentos conjugais. À medida em que as mulheres conquistaram, nas últimas décadas, mais espaços no mercado de trabalho, elas também se expuseram mais a traírem seus cônjuges, ao mesmo tempo em que se tornaram amorosamente mais exigentes.

Desconstruir a conjugalidade após a separação e, simultaneamente, reconstruir a identidade individual, é um processo lento e vivenciado com dificuldade pelos excônjuges. A vivência de uma maior liberdade se mistura com o sentimento de solidão, tornando os primeiros tempos após a separação, particularmente, difíceis para homens e mulheres. Mais acostumadas a falar sobre os sentimentos e mais motivadas a explicar e discutir os relacionamentos, as mulheres parecem conseguir com mais facilidade descrever o 
gratificante, mas também penoso processo de reconstrução da identidade individual, após a dissolução do casamento.

Ao constatarmos que o número de separações conjugais, na população geral, está crescendo muito na atualidade, podemos reafirmar que, hoje, homens e mulheres buscam relacionamentos amorosos mais verdadeiros e gratificantes e que, talvez por isso, tantos casamentos se dissolvam. Compreender melhor como os sujeitos desta população vivenciam o doloroso processo de dissolução da conjugalidade contribui, sem dúvida, de maneira relevante para promover um atendimento clínico mais contextualizado aos casais que buscam ajuda psicoterápica, tendo como uma das questões a dissolução, ou não, do laço conjugal.

\section{Agradecimentos}

Trabalho desenvolvido com apoio do CNPq e da FAPERJ, e com a colaboração das bolsistas de iniciação científica Cristina Ribeiro Teixeira Dantas, Ilana Cytrynbaum, Julia Galper, Maria Fernanda Borges Vaz de Oliveira, Mariana Santiago de Matos, Renata Brasileiro, Samantha Lemos Ferreira da Silva e da bolsista de apoio técnico Carolina Marinho Amado.

\section{Referências}

Bardin, L. (1979). Análise de conteúdo. Lisboa: Martins Fontes.

Berger, P., \& Kellner, H. (1970). Marriage and the construction of reality. In P. H. Dreitzel (Org.), Recent Sociology (pp. 20-38). Nova York: MacMillow.

Buss, D. \& Barnes, M. (1988). Preferences in human mate selection. Journal of Personality and Social Psychology, 50, 559-570.

Caruso, I. (1989). A separação dos amantes. São Paulo: Diadorim Cortez. (Texto original publicado em 1968)

Cavalcante, A. M. (1993). Por que os casais se separam? Nova Perspectiva Sistêmica, 4(2), 13-18.

Cherman, S. (1993). Sexo x afeto. Rio de Janeiro: Sathya.

Cleek, M., \& Pearson, T. (1985). Perceived causes of divorce: an analysis of interelationships. Journal of Marriage and the Family, 47, 179-183.

Demo, D. H., \& Acock, A. C. (1988). The impact of divorce on children. Journal of Marriage and the Family, 50, 619-648.

Dias, M. V. (2000). A construção do casal: um estudo sobre as relações conjugais contemporâneas. Tese de Doutorado não-publicada, Pontifícia Universidade Católica do Rio de Janeiro.

Faria-Leitão, C. (1996). O prolongamento da adolescência: impasses na separação subjetiva entre pais e filhos. Dissertação de Mestrado nãopublicada, Pontifícia Universidade Católica do Rio de Janeiro.

Féres-Carneiro, T. (1987). Aliança e sexualidade no casamento e no recasamento contemporâneo. Psicologia: Teoria e Pesquisa, 3(3), 250-261.

Féres-Carneiro, T. (1995). Casais em terapia: um estudo sobre a manutenção e a ruptura do casamento. Jornal Brasileiro de Psiquiatria, 44(2), 67-70.

Féres-Carneiro, T. (1997). Escolha amorosa e interação conjugal na heterossexualidade e na homossexualidade. Psicologia: Reflexão e Crítica, 10(2), 351-368.

Féres-Carneiro, T. (1998). Casamento contemporâneo: o difícil convívio da individualidade com a conjugalidade. Psicologia: Reflexão e Crítica, 11(2), 379-394.

Féres-Carneiro, T. (2001). Casamento contemporâneo: construção da identidade conjugal. In T. Féres-Carneiro (Org.), Casamento e família: do social à clínica (pp. 67-80). Rio de Janeiro: Nau.
Giddens, A. (1992). A transformação da intimidade, sexualidade, amor e erotismo nas sociedades modernas. São Paulo: Editora da Universidade Estadual Paulista.

Goldenberg, M. (1991). Ser homem, ser mulher: dentro e fora do casamento. Rio de Janeiro: Revan.

Goldenberg, M. (2000). O macho em crise. In M. Goldenberg (Org.), Os novos desejos (pp. 15-39). São Paulo: Record.

Gottman, J. M. (1994). Why marriages succeed or fail. Nova York: Simon \& Schuster.

Instituto Brasileiro de Geografia e Estatística. (1996). Anuário Estatístico Brasileiro. Brasília: Autor.

Jablonski, B. (1998). Até que a vida nos separe: a crise do casamento contemporâneo. Rio de Janeiro: Agir.

Kitson, G. C., \& Morgan, L. A. (1990). The multiple consequences of divorce: a decade review. Journal of Marriage and the Family, 52, 913-924.

Magalhães, A. S. (1993). Individualismo e conjugalidade: um estudo sobre o casamento contemporâneo. Dissertação de Mestrado não-publicada, Pontifícia Universidade Católica do Rio de Janeiro.

Maldonado, M. T. (1986). Casamento - término e reconstrução. Petrópolis: Vozes.

Nolasco, S. (1998). Um homem de verdade. São Paulo: SENAC.

Rasmussen, P. K., \& Ferraro, K. J. (1991). The divorce process. In J. N. Edwards \& D. H. Demo (Orgs.), Marriage and family in transition (pp. 65-85). Boston: Allyn \& Bacon.

Singly, F. (1988). Un drôle de je: le moi conjugal. Dialogue, 102(4), 3-5.

Trevisan, J. S. (1998). Seis balas num buraco só: a crise do masculino. Rio de Janeiro: Record.

Vaitsman, J. (1994). Flexíveis e plurais. Rio de Janeiro: Rocco.

Veiga-da-Silva, C. E. (1997). Partindo alianças, rompendo laços e seguindo em frente: um estudo sobre o processo de separação conjugal. Dissertação de Mestrado não-publicada, Pontifícia Universidade Católica do Rio de Janeiro.

Veiga-da-Silva, C. E. ( 2001). Sem "nós” dois, o que resta sou eu: os caminhos para a separação conjugal. Tese de Doutorado não-publicada, Pontifícia Universidade Católica do Rio de Janeiro.

White, L. K. (1990). Determinants of divorce: a review of research in the eighties. Journal of Marriage and the Family, 52, 904-912.

Willi, J. (1995). A construção diádica da realidade. In M. Andolfi, C. Angelo \& C. Saccu (Orgs.), O casal em crise (pp. 15-27). São Paulo: Summus.

Woods, E. M. A. S. (1987). Um estudo sobre o recasamento no Brasil. Dissertação de Mestrado não-publicada, Pontifícia Universidade Católica do Rio de Janeiro.

Zagury, T. (2000). O adolescente por ele mesmo. Rio de Janeiro: Record. 
1 Para identificação dos participantes, usamos na seguinte ordem, os símbolos M (mulher), H (homem), 1 (1 $1^{\underline{a}}$ faixa etária), 2 ( $2^{\underline{a}}$ faixa etária), de 1 a 8 (enumeração dos participantes dentro de cada um destes subgrupos).

Terezinha Féres-Carneiro, doutora em Psicologia Clínica, Pontifícia Universidade Católica de São Paulo, é professora titular no Departamento de Psicologia da Pontifícia Universidade Católica do Rio de Janeiro. Endereço para correspondência: Rua General Góes Monteiro, nํㅜ 8, bloco D, Apto. 2403, 22290-080, Rio de Janeiro, RJ. Tel.: 21 2285-2546. Fax: 21 2285-6119. E-mail: teferca@psi.puc-rio.br 